\title{
Development of technology for bakery products
}

\author{
Liliya ALASHBAYEVA $^{1 *}$ (D), Dinara SHANSHAROVA² (D), Aizhan MYNBAYEVA ${ }^{3}$ (D), Assel BORANKULOVA ${ }^{3}$ (D), \\ Begzada SOLTYBAYEVA ${ }^{3}$ (D)
}

\begin{abstract}
The purpose of this study is to create an assortment of whole grain wheat bread that is resistant to microorganisms and has high nutritional value. The research was carried out on the microbiological purity of whole wheat flour, the inhibitory effect of plant extracts on thermophilic bacteria detected in flour and the amount of biologically active additives and vegetable raw materials in the product. The study revealed thermostable types of bacteria in the flour. $1 \mathrm{~g}$ of whole grain flour was found to contain $92 \mathrm{CFU} / \mathrm{g}$ of Bacillus cereus and $16 \mathrm{CFU} / \mathrm{g}$ of Bacillus mesentericus. As a result of the inhibition of the bacteria Bacillus cereus and Bacillus mesentericus, cabbage juice (Brássica olerácea) has a bacteriostatic effect in addition to bactericidal activity, that is, it prevents the growth of bacteria. In the analysis of the physical and chemical characteristics of the finished product, we can see a decrease in the acidity of the bread in the functional direction. And as the volume of functional bread increases, so does its porosity. In terms of own volume, it increased by $22.4 \%$ compared to the control.
\end{abstract}

Keywords: whole grain flour; infection; bread and bakery products; vegetables; inhibition.

Pratica Application: Obtaining bread and bakery products from whole grain flour with increased biological value and with a long shelf life.

\section{Introduction}

The basis of modern concepts of healthy nutrition is the developed concept of optimal nutrition, which provides for the need to fully meet the needs of the body. An important component of a healthy diet is crops, vegetables, fruits and berries, as they are the main source of vitamins and dietary fiber (Johnson \&Wallace, 2019; Gubanichina,2017). Currently, much attention is paid in the food industry to the development of new types of bakery products from whole grain flour or with the introduction of grain crops. Whole grain flour (WGF) is flour made from grain that is not peeled from the outer layers of the endosperm, germ, and membrane. Without them, the grain is a varietal product with high carbohydrate content, causing difficulty in the functioning of the gastrointestinal tract, obesity and other diseases. The choice of the added additive in the production of flour culinary products is related to the chemical composition of whole wheat flour and the degree of its effect on the human body (Agiriga, 2014; Han \&Koh, 2011; Guijarro-Fuertes et al., 2019).

Since whole-grain flour is not cleaned of the outer layer of the endosperm, the seeds are seeded with microbiological fungi and spore-forming bacteria that are capable of producing toxic substances by chemical nature (Belokurova \& Maslova, 2017; Yakiyayeva, et al., 2016). Eating foods contaminated with pathogenic microflora causes human disease.

The seediness of grain not only leads to spoilage of food, but also to a decrease in the quality of food products, which has an undesirable effect on the quality of the finished product and human health in general, which is a worldwide safety problem.

From the data of Table 1 it can be seen that the number of control bacteria (bread from the first grade of flour) and experimental samples (bread from whole grain flour) 48 hours after baking were contaminated with microbiological pathogens of spoilage of bread.

It should be noted that the number of mesophilic aerobic and facultative anaerobic microorganisms 48 hours after baking in the test samples is greater than in the control, which can be explained in whole grain flour is a shell of grain that is connected with the soil flora. Therefore, to suppress the suppressed microorganisms, a lysozyme-containing biopolymer complex (LBC) obtained from white cabbage according to the method developed by S.A. Ozolinam (Kokhmetova et al., 2014; Selivanscaya, 2013; Madruga et al., 2020).

Calcium is one of the most beneficial elements of human health (Navrotskyi et al., 2019). Without this, a person cannot live. It is necessary for the heart, muscles and nerve cells. However, calcium can only function in combination with other elements. Therefore, without phosphorus, it is impossible to maintain healthy bones and teeth, and without magnesium, calcium cannot support the cardiovascular system. Phosphorus and magnesium are found in sufficient quantities in sesame and chia seeds, along with calcium, which is necessary for bone 
Table 1. Microbiological indicators of the studied bread products.

\begin{tabular}{ccccc}
\hline \multirow{2}{*}{ Indicators } & & The value of indicators & Experience & ND on test methods \\
\cline { 2 - 4 } QMAFAnM, CFU/g & 1 grade flour & WGF & not detected & SS 10444.15 \\
Mold, CFU/g & $0,5^{*} 10^{2}$ & $9,7^{\star} 10^{2}$ & not detected & SS 10444.12 \\
Yeast, CFU/g & less than 10 & less than 10 & not detected & SS 10444.12 \\
\hline
\end{tabular}

structure and to support the vascular system (Iztayev et al., 2018; Andrushenko, et al., 2015; Franco et al., 2020).

Calcium absorption is a very complex process involving vitamins and minerals. Therefore, all the raw materials that make up the new functional bread are rich in various vitamins and minerals.

The purpose of this study is to consider the possibility of predicting and varying quality indicators of bread products by introducing various dosages of lysozyme, sesame and chia in whole grain wheat flour. To assess the feasibility of using the selected additive, an analysis of the physicochemical, organoleptic and microbiological quality indicators of bread products was carried out and samples with the best indicators were identified. For comparison, we used samples of products from wheat flour of the first grade, prepared according to the classical recipe. Prototypes were prepared according to a similar recipe with the replacement of wheat flour of the first grade with whole grain wheat flour with the addition of lysozyme, sesame and chia. For products recognized as the best, a qualimetric quality assessment was carried out, which takes into account the totality of organoleptic, physicochemical and microbiological indicators of finished products (Naumenko et al., 2018; Cavalcante et al., 2019). The quality indicators of products, based on which a qualimetric quality assessment was carried out, are given in the Table. 1.

\section{Materials and Methods}

For research, wheat grain of "Daulet" variety was used - a variety bred at the "Kazakh Research Institute of Agriculture and Plant Growing". Whole grain flour was obtained by grinding in a CD1 mill (CHOPIN Technologies, France).

As a lysozyme-containing raw material of plant origin used extracts from vegetables in the form of juices. Sample $N^{\circ} 1$ - ginger juice, sample № 2 - turnip juice, sample No 3 - cabbage juice, sample No 4 - garlic juice, sample No 5 - radish juice. Previously, the juices were filtered using a syringe filter with a pore diameter of $0.22 \mu \mathrm{m}$, to ensure purity and prevent possible pathogenesis.

\subsection{Microbiological reagents and equipment}

Solutions and nutrient media: Muller-Hintton Agar (MHA), Muller - Hinton broth (MCHB), $0.9 \%$ sodium chloride solution (saline solution).

Equipment: DEN-1 densitometer (Latvia), Comfort thermoshaker (Germany), lb 210-A analytical balance (Russia), PB11 pH meter (Germany), SystecV-120 vertical autoclave (Germany), BD-115 thermostat (Germany), BioIIA/G laminar box (Spain), IKA MS3 Digital shaker (Germany), Eppendorf dispenser (1-10 ml, 100-1000 $\mu \mathrm{l}, 20-200 \mu \mathrm{l}, 0.5-10 \mathrm{MKL}$ ) (Germany), haakep14 thermobar (Germany), arium 611 VF water treatment system (Germany).

\subsection{Microbiological control of bread}

The primary identification of isolates, obtaining pure cultures, the study of morphological, cultural, tinctorial and physiological and biochemical properties was carried out according to the method of "Determinant of the bacteria of Bergey".The quantitative content of spore bacteria was determined by the Koch method. Each breeding was seeded on a dense nutrient medium of TSA (trypton-soy agar). Cups with crops were incubated in a thermostat at $(37 \pm 1)^{\circ} \mathrm{C}$ for 72 hours.

Biochemical, tinctorial and morphological tests were carried out: mobility was determined by seeding-injection in semi - liquid agar; lecithinase activity - by seeding on ZHSA (yolk - salt agar), catalase activity-by adding culture in a few drops of $3 \%$ hydrogen peroxide on a slide, starch hydrolysis, fermentation of mannitol, salicin and xylose was determined by seeding-injection in agar with appropriate carbohydrates and phenolic red, as an indicator. Hemolytic activity was determined by seeding on cups with $5 \%$ blood agar. The Voges-Proskauer reaction was determined on a standardized MR-VP medium. The tinctorial properties of the isolates were studied by painting the smears by Gram using a standard commercial kit and further light microscopy.

\subsection{Determination of antimicrobial activity}

To prepare the inoculum, aliquot of the daily-cultured test strain was placed in a sterile tube with $5 \mathrm{ml}$ of $0.9 \% \mathrm{NaCl}$, then placed in a DEN-1 densitometer to measure the optical density (turbidity) and, accordingly, to achieve the desired concentration of the microorganism. The density of the primary suspension should be $0.5 \mathrm{Mcfarland}$ units, which corresponds to $1.5 \times 108 \mathrm{CFU} / \mathrm{mL}$.

Antimicrobial activity was determined by double-batch dilutions in a liquid nutrient medium-Muller-Hinton broth (standard medium for the study of antibiotic sensitivity), according to the international standard CLSI M100-S25, 2015 "Performance Standards for Antimicrobial Susceptibility Testing" - M100-S25, 2015, - Vol 35 - No 3 and guidelines "Guidelines for determining the sensitivity of microorganisms to antibacterial drugs. MUC 4.12.1890-04. Moscow. 2004».

After a series of dilutions, $0.05 \mathrm{ml}$ of test strains of microorganisms in concentrations of $1.5 \times 106 \mathrm{CFU} / \mathrm{ml}$ were added to all test tubes in three repetitions. The samples were incubated for 18-24 hours at a temperature of $37 \pm 1^{\circ} \mathrm{C}$. At the end of the incubation time, seeding was performed on Petri 
dishes to determine living cells. After seeding, the cups were placed in a thermostat for 18-24 hours at a temperature of $37 \pm$ $1{ }^{\circ} \mathrm{C}$ for bacteria.

The results were taken into account based on the presence of visible growth of microorganisms on the surface of a dense nutrient medium. Minimal bactericidal dilution was considered the smallest dilution that suppressed the growth of microorganisms.

\subsection{Bread making technology}

The safe method of preparation involves the introduction of all raw materials when kneading the dough: the use of wholegrain flour, "Almaty" yeast, table salt and drinking water, juice of lysozyme-containing raw materials to suppress bacteria of the genus Bacillus, sesame and Chia seeds.

Pre-prepare the main and auxiliary raw materials: water is brought to a temperature of $32{ }^{\circ} \mathrm{C}$, yeast is dissolved in it to prepare a yeast suspension. The juice of the lysozyme-containing raw material is introduced into the water, sesame and Chia seeds are mixed with flour. Prepare and filter a salt solution with a concentration of 0.26 . The dough is kneaded in a TEDDY mixer (bear Varimixer, Denmark).

The humidity of the test should be about $49 \%$ at an initial temperature of $28-30^{\circ} \mathrm{C}$. Fermentation of the test is carried out at a temperature of $30-31^{\circ} \mathrm{C}$ for about 150 minutes. The duration of fermentation of the test is $210 \mathrm{~min}$. The finished dough is divided into pieces weighing 400 grams. Manually round the dough pieces and place them for proofing in the Sinmag CLT0409 proofing Cabinet at a temperature of $32-35^{\circ} \mathrm{C}$ for 40 minutes with a relative humidity of $85 \%$. Baking bread is carried out in a convection, rotary mini-oven S 400 for 35-40 minutes with steam cooling of the baking chamber at a temperature of 200$210^{\circ} \mathrm{C}$. Baked bread is cooled and stored at room temperature.

\section{Organoleptic evaluation of bread}

The prepared whole wheat bread was allowed to cool for 1 hour at room temperature, and then evaluated. A group of ten judges was created (using the questionnaire) of regular bread consumers, the bread was examined using a 5-point scale with a scorecard from 1 to 5 , where $1=$ I really dislike it, $3=$ satisfies and 5 = really like. Product Evaluation Options: crumb grain, texture, crumb color, aroma and general acceptability.

\section{Results and Discussion}

\subsection{Isolation of bacterial relatives of Bacillus from whole grain flour}

After the incubation time, only $1 \times 10-1$ primary breeding revealed microorganisms of the Bacillus spp breed. For further research, two types of trypton grafted into soy agar plates were identified. The number of forming colonies in $1 \mathrm{~g}$ of dry whole wheat flour: for colonies of the first type (gray-white color of dry crumpled colonies) - $92 \mathrm{CFU} / \mathrm{g}$, for colonies of the second type (beige-brown-dry mint colonies) - $16 \mathrm{CFU} / \mathrm{g}$.

Generalized results of the morphological, tinctorius and biochemical characteristics are shown in Table 2.

Summarizing the morphological, cultural, tinctorial and biochemical characteristics, $\mathrm{N}^{\circ} 1$ colony is a motor, lecithinase, catalase and hemolytic activity, the endospores of which are located in the center, growing in the middle in the form of gray wrinkled dry wrinkled colonies. They have a positive Foges-Proskuer reaction (enzymatic glucose under anaerobic conditions), hydrolysis of starch, fermentation of xylose and salicylic acid, and no fermentation of mannitol. These symptoms are similar to those of Bacillus cereus.

No 2 colonies are characterized by the growth of a dense nutrient medium of dry wrinkled orange-brown colonies. Cells in the placenta consist of thin gram-positive nuclei with endospores. According to biochemical studies, the cells are mobile, catalase-positive, have hemolytic activity, ferment mannitol and xylose. There is no leticinase activity, the VogesProskauer reaction is negative, the starch is not hydrolyzed and the salicin is not fermented. Based on the study, it is believed that the isolation of $\mathrm{N}^{\circ} 2$ colonies can be attributed to the species Bacillus mesentericus.

\subsection{Antimicrobial activity of phytoextracts against isolated Bacillus families}

The results of the study of the antibacterial activity of samples against Bacillus bacteria are given in Figure 1.

Table 2. Basic biochemical, morphological and tinctorial properties of isolated bacterial colonies.

\begin{tabular}{|c|c|c|}
\hline Tests & Colony No 1 & Colony No2 \\
\hline Cell morphology and tinktoriology & $\begin{array}{l}\text { Gram-positive short sticks with centrally } \\
\text { positioned endospores }\end{array}$ & Gram-positive thin sticks forming endospores \\
\hline Colony Type & Dry wrinkled, grayish-white colony & Yellowish-brown, dry, wrinkled colonies \\
\hline Mobility & + & + \\
\hline Lecithinase activity & + & - \\
\hline Catalase activity & + & + \\
\hline Voges-Proskauer test & + & - \\
\hline Hemolytic activity & $+(\alpha$-hemolysis $)$ & $+(\alpha$-hemolysis $)$ \\
\hline Hydrolysis of starch & + & - \\
\hline Hydrolysis of mannitol & - & + \\
\hline Xylose Fermentation & + & + \\
\hline Salicin & + & - \\
\hline
\end{tabular}




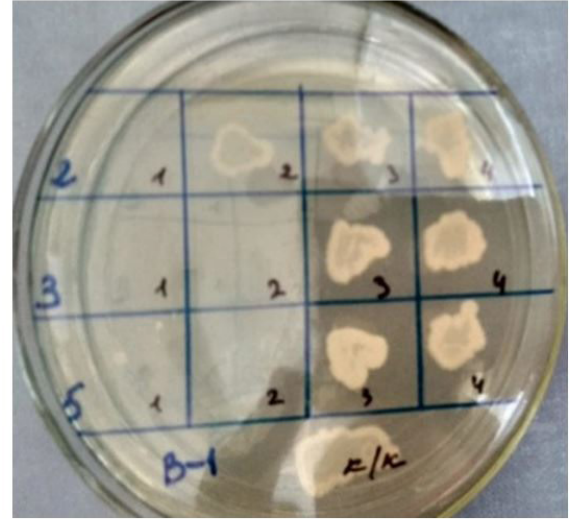

a)

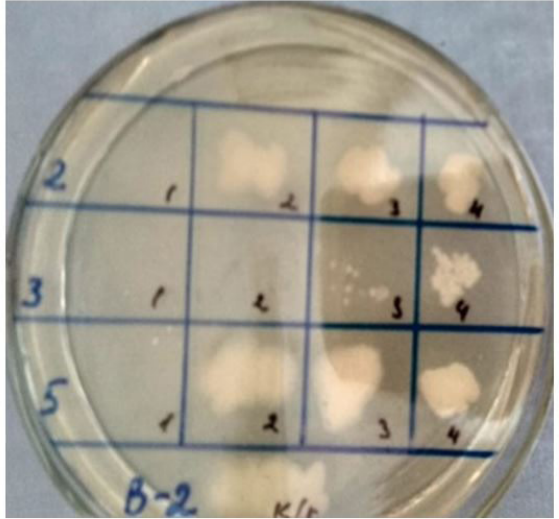

b)

Figure 1. Results of antimicrobial activity of samples obtained by serial dilution:a)Inhibition of Bacillus cereus strain by dilution with vegetable extracts.b) Inhibition of Bacillus mesentericus strain by dilution with vegetable extracts; 2 - inhibition with turnip extract, 3-inhibition with cabbage extract; 5 - inhibition with radish extract.

The Figure 1 below shows that not all samples are effective against bacterial strains.

Analysis of the activity of phytoextracts showed that 1 and 2 sample has bactericidal activity in both strains at 1:1 dilution.

№ 3 samples have a pronounced bacteriostatic effect when diluted 1:2 against Bacillus cereus, and when diluted 1:2 to 1:8 against Bacillus mezentericus.

Sample N ${ }^{\circ}$ at 1: 2 dilution inhibited the growth of Bacillus cereus strain, and at 1:1 dilution inhibited the growth of Bacillus mesentericus strain.

Sample $\mathrm{N}^{\circ} 1$ and sample $\mathrm{N}^{\circ} 4$ were ineffective against these test strains.

Comparing the results, the most effective in the fight against bacteria of the genus Bacillus is the sample $\mathrm{N}^{\circ} 3$, which, in addition to bactericidal activity, has a bacteriostatic effect, i.e. inhibits the growth and reproduction of bacteria. Samples $\mathrm{N}^{\circ} 2$ and $\mathrm{N}^{\circ} 5$ have a bactericidal effect, inhibiting bacterial growth only in 1: 1-1: 6 solutions.

According to the results of antimicrobial activity, No3 samples - cabbage juice - were further studied to inhibit microbiological damage to bread.

\subsection{Preparation of a recipe for whole grain bread of functional purpose}

To build a mathematical model and select the optimal parameters of the test preparation process, an experimentalstatistical approach was applied. As the output parameter $y$, characterizing the physicochemical properties of the finished bread products, the specific volume of products $\left(\mathrm{cm}^{3} / 100 \mathrm{~g}\right)$ was used. The main factors selected were: $\mathrm{x}_{1}$ - dosage of lysozyme, $\%$ of the total weight of flour in the dough; $\mathrm{x}_{2}$ - sesame, $\%$ to the total mass of flour in the dough, $\mathrm{x}_{3}$ - chia, $\%$ to the total mass of flour in the dough. The selected factors do not correlate with each other (Table 3 ).
Table 3. Planning characteristics.

\begin{tabular}{lcccc}
\hline \multicolumn{1}{c}{ The name of indicators } & & $\mathrm{x}_{1}$ & $\mathrm{x}_{2}$ & $\mathrm{x}_{3}$ \\
\hline Upper Factor Levels & $(+1)$ & 1,5 & 2 & 3 \\
Lower Factor Levels & $(-1)$ & 0,5 & 1 & 1 \\
Main Factor Levels & $(0)$ & 1 & 1,5 & 2 \\
Factor Variation Levels & & 0,5 & 0,5 & 1 \\
Relations & & 2 & 3 & 2 \\
\hline
\end{tabular}

To build a mathematical model that adequately describes the dependence of the selected output parameter on the studied factors, an active experiment was conducted on a central compositional uniform-rotatable plan system. To exclude the influence of uncontrolled parameters on the experimental results, the order of experiments was randomized using a random number table. In the table. Figure 3 shows the arithmetic mean values of the response function in two parallel experiments.

Statistical processing of experimental data consisted of calculating estimates of the regression coefficients, checking their significance, evaluating the reproducibility of experiments and establishing the adequacy of the obtained equation. As a result of statistical processing of the experimental data, a regression equation is obtained that adequately describes the dependence of the specific volume of the finished bread product on the dosage of additives for whole-grain wheat flour LBK, sesame, and chia (Equation 1):

$$
\begin{aligned}
& Y_{1}=250,741+2,06 x_{1}+0,29 x_{2}+2,32 x_{3}-0,25 x_{1} x_{2}- \\
& 2,75 x_{1} x_{3}-1,5 x_{2} x_{3}-5,96 x_{1}{ }^{2}-5,79 x_{2}{ }^{2}-2,61 x_{3}{ }^{2}
\end{aligned}
$$

Thus, the possibility of predicting and varying the quality indicators of bread products by making various dosages is confirmed: LBC $-1 \%$, sesame $-1.5 \%$ and chia $-2.5 \%$ to $100 \mathrm{~g}$ of whole grain wheat flour.

To obtain a surface response when choosing the combined effect of additives on the specific volume of bread, the results are analyzed: 
Sections A of Figure 1 show the dependence of the specific volume of bread $\left(\mathrm{x}_{1}\right)$ on LBC and $\mathrm{x}_{2}$ sesame seeds. As can be seen from the figure, $x_{1}=1.01$ percent and the amount of sesame was $\mathrm{x} 2=1.51$ percent. The largest peak in the quality of bread, depending on the LBC and sesame, was $\mathrm{E}=253 \mathrm{~mm}$.

Sections B of Figure 1 show the dependence of bread quality on $\left(\mathrm{x}_{1}\right)$ LDC and $\left(\mathrm{x}_{3}\right)$ chia seeds. $\mathrm{x}_{1}=0.98$ percent and $\mathrm{x}_{3}=2.49$ percent. The highest efficiency of bread quality was achieved by the size of $\mathrm{E}=252 \mathrm{~mm}$.

Sections B of Figure 1 show the dependence of bread quality on $\mathrm{x}_{2}$ sesame seeds and $\mathrm{x}_{3}$ chia seeds. Here, the value of sesame seeds was $\mathrm{x}_{2}=1.5$ percent and the value of chia seeds was $\mathrm{x}_{3}=2.50$ percent. The highest efficiency of bread quality was achieved with the size $\mathrm{E}=251 \mathrm{~mm}$.

Graphical analysis (Figure 2) showed that the following percentages are the most optimal in terms of $\%$ of the mass of wheat flour in the dough: the biological complex with lysozyme - $0.72 \%$, sesame $-2.7 \%$, chia $-3.27 \%$.

From the obtained mathematical data, a generalized complex quality indicator was determined: control - 1.0; sample with $1 \%$ LBC ; $1.5 \%$ sesame seeds and $2.5 \%$ chia. To determine the effect of whole grain wheat flour on the microbiological parameters of bread products, we determined the number of aerobic and facultative anaerobic microorganisms, as well as the number of yeast and mold. Microbiological analyzes were performed 12 and 48 hours after baking products (Table 1).

Using the data of the optimal dosages of the mathematical model, bread was baked and the physicochemical and organoleptic properties were studied (Table 4).

For products recognized as optimal dosages, a qualimetric quality assessment was carried out, which takes into account the

Table 4. Quality indicators of the studied bread products.

\begin{tabular}{ccc}
\hline \multirow{2}{*}{ Indicators } & \multicolumn{2}{c}{ Indicator values } \\
\cline { 2 - 3 } & Control & Experience \\
\hline Appearance & 4 & 5 \\
The form & 4 & 5 \\
Colour & 5 & 5 \\
Bakedness & 5 & 5 \\
Kneading & 5 & 5 \\
Taste & 4 & 5 \\
Smell & 48 & 5 \\
& 7 & 47,5 \\
Humidity\% & 55 & 6,5 \\
Acidity, degrees & 645 & 67 \\
Porosity, $\%$ & & 936,5 \\
Volume, cm3 & &
\end{tabular}
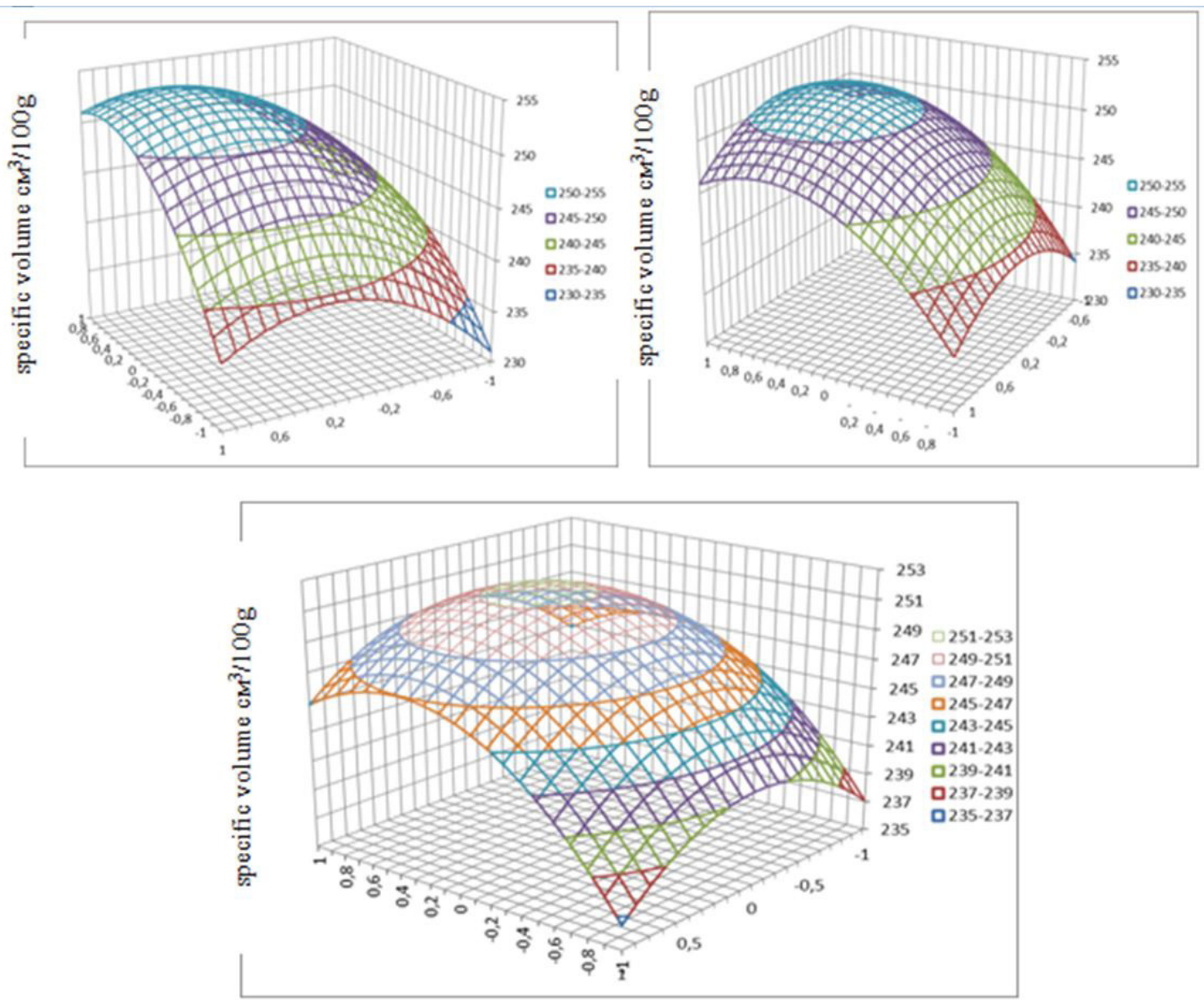

Figure 2. Responsesurface and non-linear level of dosages of LBC, sesame and chiy per specific bread volume for Y1. 
totality of the organoleptic and physicochemical characteristics of the finished products. Compared to the control (whole-grain bread) functional bread in terms of bread quality indicators is the best.

There were no significant differences in the sensory characteristics of whole grain bread samples in terms of baking, kneading, taste (Table 1). However, additives added to wholegrain bread have been shown to have a positive effect on the sensory properties of the product. According to the analysis of the physical and chemical characteristics of the product, the moisture and acidity of the experimental sample decreased compared to the control, and as the product increased, the porosity also increased. Biologically active additives and vegetable raw materials did not adversely affect the quality of the product and consumer perception.

In addition, the effect of LBC and sesame and chia grains on the specific gravity of whole grain bread was studied (Figure 3 ).

Despite the nutritional value of whole grain bread compared to whole grain bread, it is limited by consumers for several reasons: small size due to lack of gluten, poor structure (Schwartau et al., 2014). However, under the influence of additives added to whole grain flour, you can see an increase in the specific volume of bread.

The results of the following research should be submitted for discussion on the basis of research and developed materials.

1. Bacteria of Bacillus cereus and Bacillus mesentericus were found in whole wheat flour. The number of colony-forming microorganisms in $1 \mathrm{~g}$ of dry wheat flour was $92 \mathrm{CFU} / \mathrm{g}$ for Bacillus cereus and 16 CFU / g for Bacillus mesentericus. These values indicate the safety of the finished product (GOST 10444.15-94). Spores of the genus Bacillus, which enter the human body, can cause significant dysfunction of the immune system, gastrointestinal tract, liver, respiratory system and nervous system. Therefore, even if spore bacteria do not cause potato disease in bread, it is better not to have them in the finished product. They may be present in large fractions of whole grain breads. The source of infection may be the air in the bakery. Statistics show that over the past decade, the number of small and medium-sized enterprises engaged in the production of bread and bakery products using non-traditional vegetable raw materials such as bran, seeds, grains and legumes has increased. Such products are in demand among consumers, but the raw material is often a source of Bacillus bacteria, which requires the use of safe preservatives.

2. Lysozyme is found in almost all living things, which is associated with its specific protective function (Voblikov et al., 2001). Lysozyme is a hydrolytic enzyme that selectively releases polysaccharides from the bacterial cell wall. This is a small protein with a molecular weight of about 15 thousand. The enzyme is relatively thermostable and can withstand pasteurization temperatures (Tursunbayeva et al., 2019). Five types of plants with lysozyme were used: ginger, garlic, turnip, cabbage, radish juice. Cabbage juice, which has a high performance in the study of antimicrobial properties

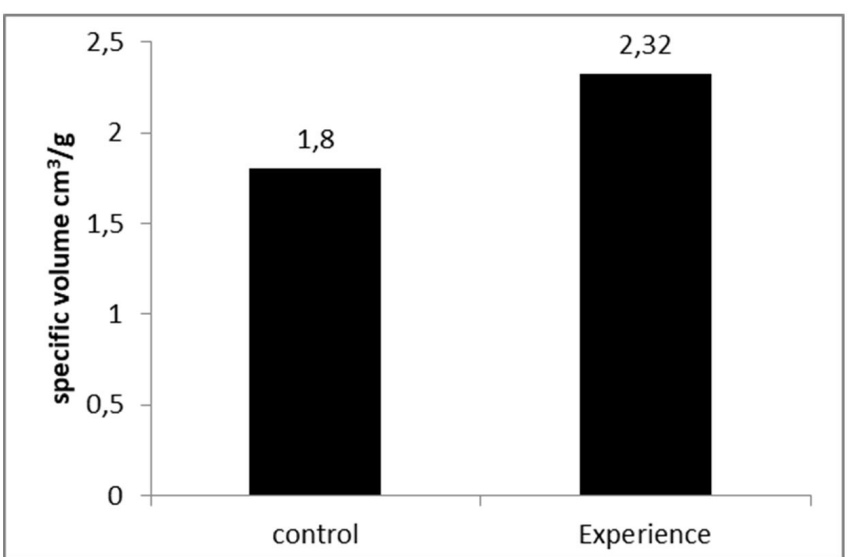

Figure 3. The effect of additives is the specific volume of whole wheat bread.

of phytoextracts against the bacteria Bacillus cereus and Bacillus mesentericus. Along with the bactericidal activity of cabbage juice, bacteriostatic effect was observed. A biologically active complex containing lysozyme was obtained on the basis of cabbage extract.

3.3. Organoleptic and physicochemical properties of whole grain wheat bread made with a combination of biologically active complex with lysozyme and vegetable raw materials (sesame and chia seeds) were studied. Compared with the control of organoleptic properties of the bread under study, it had better results in appearance, shape, color and odor. In terms of its own volume, it was $22.4 \%$ higher than the control.

\section{Conclusions}

Whole grain bread can be used as a functional product available to all social groups. However, components of the outer layers of the grain are carriers of Bacillus bacteria. Therefore, the quality of whole grain bread obtained by using sesame and chia seeds to increase the nutritional value of a biologically active additive containing lysozyme to inhibit the microbiological purity of bread. Microbiological studies have provided the basis for further scientific research in the study of sensory characteristics of bread. Informing the public about the nutritional benefits of functional products, using lysozyme-containing complex and vegetable raw materials (sesame seeds and chili seeds) expands the range of bread and bakery products.

\section{References}

Agiriga, A. N. (2014). Effect of whole wheat flour on the quality of wheatbaked bread. Global Journal of Food Science and Technology, 2(3), 124-133.

Andrushenko, S. B., Perunova, N. B., \& Buharin, O. V. (2015). Molecular mechanisms of bacterial interaction with lysozyme and their role in the microsymbiocenosis. Advances in Medicine and Biology, 135(5), 453-463.

Belokurova, E. V., \& Maslova, V. A. (2017). Prediction and variation of quality indicators of flour culinary products with the introduction of whole grain wheat flour. Product Quality and Safety, 6, 26-27. 
Cavalcante, R. B. M., Morgano, M. A., Gloria, M. B. A., Rocha, M. M., Araujo, M. A. M., Moreira-Araujo, R. S. R. (2019). Mineral content, phenolic compounds and bioactive amines of cheese bread enriched with cowpea. Journal of Food Science and Technology, 39(4), 843-849. http://dx.doi.org/10.1590/fst.11718.

Franco, V. A., Garcia, L. G. C., \& Silva, F. A. (2020). Addition of hydrocolidics in gluten-free bread and replacement of rice flour for sweet potato flour. Journal of Food Science and Technology, 40(Suppl. 1), 88-96. http://dx.doi.org/10.1590/fst.05919.

Gubanichina, E. V. (2017). Proper nutrition as a factor in maintaining human health. Young Scientist, 50(184), 119-121.

Guijarro-Fuertes, M., Andrade-Cuvi, M. J., Bravo-Vásquez, J., RamosGuerrero, L., \& Vernaza, M. G. (2019). Andean blueberry (Vaccinium floribundum) bread: physicochemical properties and bioaccessibility of antioxidants. Journal of Food Science and Technology, 39(Suppl. 1), 56-62. http://dx.doi.org/10.1590/fst.30317.

Han, H. M., \& Koh, B. K. (2011). Antioxidant activity of hard wheat flour, dough and bread prepared using various processes with the addition of different phenolic acids. Journal of the Science of Food and Agriculture, 91(4), 604-608. http://dx.doi.org/10.1002/jsfa.4188. PMid:21302313.

Iztayev, A., Yakiyayeva, M., Kulazhanov, T., Kizatova, M., Maemerov, M., Stankevych, G., Toxanbayeva, B., \& Chakanova, Zh. (2018). Controlling the implemented mathematical models of ion-ozon cavitation treatment for long-term storage of grain legune crops. Journal of Advanced Research in Dynamical and Control Systems, 10(13), 672-680.

Johnson, J., \& Wallace, T. (2019). Whole Grains and their Bioactives (pp. 19-45). Hoboken: John Wiley \& Sons.

Kokhmetova, A., Sapakhova, Z., Yessimbekova, M., Yeleshev, R., \& Morgounov, A. (2014). Principles and methods of selection of grain crops at the present stage. J. Vestnik of Agricultural Science of Kazakhstan, 1, 3-19.

Madruga, K., Rocha, M., Fernandes, S. S., \& Salas-mellado, M. M. (2020). Properties of wheat and rice breads added with chia (Salvia hispanica L.) protein hydrolyzate. Journal of Food Science and Technology, 40(3), 596-603. http://dx.doi.org/10.1590/fst.12119.

Naumenko, N. V., Potoroko, I. Yu., Kretova, Yu. I., Kalinina, I. V., Paimulina, A. V., \& Caturov, A. V. (2018). On the issue of intensification of the process of grain germination. Far Eastern Agrarian Bulletin, $4(48), 109-115$.

Navrotskyi, S., Guo, G., Baenziger, P. S., Xu, L., \& Rose, D. J. (2019). Impact of wheat bran physical properties and chemical composition on whole grain flour mixing and baking properties. Journal of Cereal Science, 89(102790), 1-7. http://dx.doi.org/10.1016/j.jcs.2019.102790.

Schwartau, V., Virych, P., Makoveychuk, T., \& Artemenko, A. (2014). Calcium in plant cells. Visnyk of Dnipropetrovsk University. Biology, Ecology, 22, 19-32.

Selivanscaya I. A. (2013). Lysozyme is a promising component of functional food products. Bakery Products: Technology and Quality, 2(50), 12-13.

Tursunbayeva, Sh. A., Iztayev, A., Magomedov, M., Yakiyayeva, M. A., \& Muldabekova, B. Zh. (2019). Study of the quality of low-class wheat and bread obtained by the accelerated test method. J. Periodico Tchê Quimica, 16(33), 809-822.

Voblikov, E. M., Bukhancov, V. A., Maratov, B. K., \& Prokopec, A. S. (2001). Post-harvest processing and storage of grain. Rostov-naDonu: MarT, 229.

Yakiyayeva, M., Iztaev, A., Kizatova, M., Maemerov, M., Iztaeva, A., Feydengold, V., Tarabaev, B., \& Chakanova, Zh. (2016). Influence of ionic, ozone ion-ozone cavitational treatment on safety of the leguminous plants and oil-bearing crops at the storage. Journal of Engineering and Applied Sciences, 11(6), 1229-1234. 